\title{
Sistem Pakar Rekomendasi Obat Non-Resep Dokter dengan Metode Fuzzy Inference System Tsukamoto Berbasis Mobile Android
}

\author{
Afief Akmal (1300018056) ${ }^{a, 1}$, Andri Pranolo (60130757) b,2 \\ a Program Studi Teknik Informatika Universitas Ahmad Dahlan \\ Jl. Prof. Dr.Soepomo, Janturan, Yogyakarta 55164, Indonesia \\ ${ }^{1}$ afief.akmal.56@gmail.com; ${ }^{2}$ andri.pranolo@tif.uad.ac.id
}

\begin{abstract}
ABSTRAK
Obat pada dasarnya merupakan bahan yang hanya dengan takaran tertentu dan dengan penggunaan yang tepat dapat dimanfaatkan untuk mendiagnosa, mencegah penyakit, menyembuhkan atau memelihara kesehatan. Oleh karena itu, sebelum menggunakan obat harus diketahui sifat dan cara pemakaian obat agar penggunaannya tepat dan aman. Kurangnya informasi mengenai pengobatan dan hal-hal tentang obat, maka costumer melakukan selfregulation terhadap terapi obat yang diterimanya menyebabkan meningkatnya kasus kesalahan dalam pemberian obat sehingga menyebabkan hal hal yang lebih buruk pada keadaan costumer apotek tiga farma. Penelitian ini bertujuan untuk membangun sebuah sistem pakar yang dapat digunakan untuk merekomendasikan obat non-resep dokter, serta memberikan informasi mengenai jenis dan macam obat dengan studi kasus pada penelitian ini adalah di apotek tiga farma sejumlah 30 kasus pembelian Obat Bebas dan Obat Bebas Terbatas. Perancangan sistem ini berdasarkan arsitektur sistem pakar yaitu akuisisi pengethauan, basis pengetahuan, dan mesin inferensi yang dalam penelusuran faktanya menggunakan forward chaining dan metode pengambilan solusi yang digunakan adalah sistem inferensi fuzzy tsukamoto. Hasil dari penelitian ini adalah aplikasi sistem pakar untuk memberikan rekomendasi obat non-resep dokter dan kemudian di uji dengan menggunakanUsability Testing untuk pengujian software yang hasilnya menunjukan bahwa tiap-tiap user memiliki nilai grade B yang artinya termasuk dalam kategori excellent. Kemudian uji dengan Accuracy Testing digunakan dalam menentukan keakuratan sistem memberikan rekomendasi obat dan hasilnya mendapatkan nilai sebesar 100\% dari 15 kasus yang diujikan. Dari dua pengujian tersebut membuktikan bahwa sistem dinilai layak guna dan sesuai dengan hasil obat yang direkomendasikan pakar.
\end{abstract}

Ciptaan disebarluaskan di bawah lisensi CC-BY-SA.

Kata kunci: Android, Rekomendasi Obat, Sistem Pakar, Tsukamoto, Obat

\section{Pendahuluan}

Sistem pakar merupakan sistem yang dirancang untuk dapat menyelesaikan masalah seperti layaknya para ahli dalam bidang tertentu. Sistem pakar juga dapat digunakan oleh orang awam sebagai alternatif untuk dapat memperoleh jawaban dari permasalahannya ${ }^{[1]}$. Dari penelitian mengenai Sistem Pakar, beberapa peneliti mengembangkan Sistem Pakar dibidang Farmasi.

Dalam Bidang Farmasi sendiri, obat merupakan racun yang jika tidak digunakan sebagaimana mestinya dapat membahayakan penggunanya, tetapi jika obat digunakan dengan tepat dan benar maka diharapkan efek positifnya akan maksimal dan efek negatifnya menjadi seminimal mungkin. Oleh karena itu, sebelum menggunakan obat harus diketahui sifat dan cara pemakaian obat agar penggunaannya tepat dan aman ${ }^{[2]}$. kesalahan dalam pemberian obat menduduki peringkat pertama (24.8\%) dari 10 besar insiden yang dilaporkan dan kecacatan yang permanen pada costumer di Australia $11 \%$ disebabkan karena kegagalan komunikasi dalam pemilihan obat ${ }^{[2]}$. 
Dalam membangun sebuah sistem pakar menggunakan fuzzy logic ada terobosan baru yang memperluas konsep himpunan tegas (Crisp Sets), dalam arti bahwa himpunan tegas merupakan kejadian khusus dari himpunan fuzzy (fuzzy sets) ${ }^{[3]}$. Salah satu yaitu penggunaan Sistem Inferensi Fuzzy, yang dimana Ada tiga metode dalam sistem inferensi fuzzy yang dapat digunakan untuk menentukan jumlah produksi, yaitu: metode Tsukamoto, metode Mamdani, dan metode Sugeno ${ }^{[4]}$. Dari metode tersebut dipilihlah sistem logika fuzzy inferensi Tsukamoto dalam penentuan sistemnya karena mampu menoleransi data-data yang kurang tepat ${ }^{[5]}$.

Berdasarkan hasil observasi yang dilakukan di Apotek Tiga Farma didapatkan hasil bahwa hampir $60 \%$ costumer yang membeli obat tanpa adanya resep dokter, sehingga costumer yang belum paham mengenai pemilihan obat dapat meningkatkan prosentase kesalahan pemilihan obat, sedangkan berdasarkan hasil observasi, belum ada penunjang komunikasi pemilihan obat antara costumer dengan apoteker. Selain itu, di Apotek Tiga Farma belum ada pendataan teratur mengenai pelanggan sehingga tidak ada monitoring dari pakar dan terjadi beberapa kasus kesalah obat di apotek tiga farma.

Dari fakta-fakta tersebut maka dalam pembuatan skripsi ini bertujuan untuk dapat membuat sistem pakar dengan metode tsukamoto yang memberikan rekomendasi obat kepada costumer, membantu karyawan apotek tiga farma dalam mendata pelanggan dan disisi lain juga diperuntukan bagi pakar dalam mengawasi pemilihan obat dari pelanggan.

\section{Landasan Teori}

Penelitian ini mengacu kepada masalah yang diangkat oleh Ari Pujiantoro ${ }^{[6]}$ mengenai sistem pakar dalam mendiagnosis penyakit hati dengan metode Fuzzy Tsukamoto . dalam penelitian tersebut aplikasi yang dihasilkan berupa aplikasi desktop untuk menentukan penyakit hati dari studi kasus yang ada di RS PKU Muhammadiyah Yogyakarta. Fitur pada aplikasi ini adalah dapat menentukan jenis penyakit hati, serta memberikan informasi kepada pengguna tentang penyakit hati dari gejala yang di alami dan juga akan menampilkan penyabab penyakit beserta dengan solusi.

Penelitian lain dilakukan oleh Nabilah ${ }^{[7]}$ yang mengangkat topik mengenai penggunaan metode fuzzy inference dalam menentukan resiko penyakit payudara. Hasil dari penelitian ini adalah aplikasi berbasis website dengan fitur yang menarik seperti Memiliki database costumer, sehingga dapat mengecek riwayat penyakit costumer jika sebelumnya pernah menggunakan system tersebut, kemudian system juga dapat mengoutputkan hasil diagnosa berupa persentase kemungkinan.

Referensi lainnya adalah penelitian dari Waluyo ${ }^{[8]}$ mengenai sistem pakar dalam mendiagnosa penyakit DBD dan demam tifoid dengan metode fuzzy tsukamoto. Hasil dari penelitian ini adalah aplikasi dengan berbabasis website dengann fitur dapat menampilkan hasil diagnosa juga menyimpan laporan mengenai riwayat, dan laporan tersebut disampaikan kepada admin system yang seorang pakar, dan hasilnya dapat dicek ulang oleh pakar, sehingga persentase kesalahan diagnosa akan berkurang. Kelebihan utaman dalam penelitian ini adalah pemetaan input dan output lebih kompleks. Dapat menghasilkan output dalam bentuk persentase. Memiliki fitur laporan yang dapat dikirimkan langusung kepakar mengenai laporan penggunaan konsultasi oleh costumer.

1. Obat

Obat merupakan racun yang jika tidak digunakan sebagaimana mestinya dapat membahayakan penggunanya, tetapi jika obat digunakan dengan tepat dan benar maka diharapkan efek positifnya akan maksimal dan efek negatifnya menjadi seminimal mungkin ${ }^{[2]}$.

2. Sistem Pakar

Sistem pakar memiliki aristektur yang terdiri dari beberapa bagian utama yaitu ${ }^{[9]}$ :
a. Knowledge Base
b. Inference System
c. Working Memory
d. Explanation Facility 
e. Knowledge Acquisition

f. User Interface

3. Fuzzy Inference System Tsukamoto

Inferensi adalah proses penggabungan banyak aturan berdasarkan data yang tersedia. Komponen yang melakukan inferensi dalam sistem pakar disebut mesin inferensi. Sistem inferensi fuzzy merupakan suatu kerangka komputasi yang didasarkan pada teori himpunan fuzzy, aturan fuzzy yang berbentuk IF-THEN, dan penalaran fuzzy ${ }^{[10]}$. Dengan rumus pencarian $\mathrm{Z}$ pada metode ini adalah :

$$
\begin{aligned}
& Z=\frac{\sum(\alpha * z)}{\sum \alpha} \\
& \alpha=\frac{z-a}{b-a}
\end{aligned}
$$

Keterangan :

$\mathrm{z}=$ Nilai tegas ke-i

$\mathrm{a}=$ Nilai tegas terkecil

$\mathrm{b}=$ Nilai tegas terbesar

\section{Forward Chaining}

Forward Chaining merupakan proses data yang mulai berjalan ketika informasi tertentu diletakkan oleh pengguna. Tanda-tanda atau kunci-kunci keberhasilan akan terkumpul dengan sendirinya ketika mengara ke kesimpulan ${ }^{[10]}$.

5. Unifed Modeling Language

UML adalah suatu bahasa yang telah menjadi standar dalam industri untuk visualisasi, merancang dan mendokumentasi sistem piranti lunak.

\section{Waterfall Model}

Model Waterfall merupakan salah satu model proses perangkat lunak yang mengambil kegiatan proses dasar seperti spesifikasi, pengembangan, validasi, dan evolusi, dan merepresentasikannya sebagai fase-fase proses yang berbeda seperti analisis dan deifinisi persyaratan, perancangan, implementasi, pengujian, integrasi sistem, pengujian sistem, operasi dan pemeliharaan.

\section{Metode Penelitian}

\subsection{Obyek Penelitian}

Obyek penelitian dalam skripsi ini adalah Sistem Pakar untuk menentukan obat nonresep dokter dengan studi kasus di Apotek Tiga Farma dengan mengunakan metode fuzzy inference system tsukamoto yang berbasis mobile dalam platform Android. Model proses yang digunakan dalam penelitian ini adalah menggunakan model waterfall. Desain sistem diharapkan mampu membantu user yang telah mendaftarkan diri sebagai member di Apotek Tiga Farma untuk memastikan obat yang tepat dikonsumsi dengan gejala-gejala yang diderita, sehingga menurunkan persentase kesalahan pemilihan obat. Sistem berjalan dengan cara memasukan gejala-gejala yang dirasakan, kemudian dari hasil proses sistem akan memberikan hasil diagnosa berupa jenis penyakit, definisi penyakit, penyebab penyakit, obat non-resep yang perlu dikonsumsi dan nilai keputusan dari hasil perhitungan metode fuzzy inference systemtsukamoto sehingga user dapat langsung mengetahui obat yang tepat untuk memberikan penanganan pada penyakitnya.

\subsection{Analisis Kebutuhan}


a. Kebutuhan Alat Pengembang

Kegiatan dalam tahap ini adalah megenalisis kebutuhan untuk membangun aplikasi sistem pakar dalam merekomendasikan obat non-resep dokter bagi costumer. Kebutuhan yang dimaksud seperti kebutuhan hardware dan kebutuhan software dalam membangun aplikasi.

b. Kebutuhan Sistem

Dalam kegiatan ini adalah menganalisis kebutuhan untuk membangun aplikasi sistem pakar dalam merekomendasikan obat non-resep dokter bagi costumer berbasis mobile android. Dalam hal ini ditentukannya model-model yang nantinya akan diterapkan pada penelitian ini.

\subsection{Pengumpulan Data (Akuisisi Pengetahuan)}

Dalam pengambilan data dari pakar yang ada, ada beberapa metode yang digunakan dalam pengumpulan data atau perancangan akuisisi pengetahuan di penelitian ini.

a. Teknik Observasi

Teknik observasi ini merupakan teknik pengambilan data dengan cara mengamati langsung data, dalam hal ini pengamatan yang dilakukan adalah seperti saat pakar memilih obat bagi costumer, kemudian diamati secara seksama kapan saja pakar memberikan obat dengan gejala yang dikatakan oleh costumer.

b. Teknik Wawancara

Teknik ini merupakan teknik yang melakukan komunikasi secara langsung dengan pakar, dalam penelitian ini wawancara dilakukan kepada 2 pakar yang merupakan apoteker di Apotek Tiga Farma yaitu Suwasti Kanti, S.Farm., Apt. Dan Nining, S.Farm., Apt. Wawancara ini dilakukan dengan menanyakan mengenai beberapa data tentang kapan obat harus diberikan, berapa kali batas maksimal pengkonsumsian obat, dan beberapa pengambilan data lainnya secara komunikasi langsung.

c. Teknik Dokumentasi

Teknik ini adalah metode pengumpulan data dengan cara membaca literatur berupa buku, makalah, artikel, jurnal serta mempelajari data-data yang ada di internet yang berkaitan mengenai penelitian ini, seperti pengambilan data dari buku mengenai obat dan penyakit, dan buku penunjang lainnya.

\subsection{Perancangan Sistem}

Tahap ini merupakan tahap atau perancangan sistem yang dilakukan sebagai salah satu tahapan proses pembuatan aplikasi. Perancangan program penting sekali agar proses pembuatan aplikasi semakin terarah dan aplikasi yang dihasilkan bekerja dengan baik. Dalam pembuatan sistem pakar ini beberapa teknik yang digunakan dalam perancangan sistem dengan acuan berdasarkan arsitektur sistem pakar menurut Turban ${ }^{[10]}$ yaitu :

1. Merancang Basis Pengetahuan (Tabel Keputusan)

2. Merancang Basis Aturan (Aturan IF-THEN)

3. Penarikan Kesimpulan (FIS-Tsukamoto)

4. Perancangan Mesin Inferensi (Forward Chaining)

5. Perancangan Pemodelan Data (UML)

6. Perancangan Tabel Database

7. Interface System

Sistem antarmuka ini meliputi perancangan format menu dan perancangan interface yang akan digunakan sebagai fasilitas dialog antar sistem dan user.
a. Perancangan Lingkungan Konsultasi
b. Perancangan Lingkungan Development
c. Perancangan Tampilan Umum 


\subsection{Implementasi}

Pada tahap ini merupakan tahap untuk mengubah desain yang telah dibuat menjadi sebuah sistem yang dapat berjalan sesuai dengan kebutuhan, untuk menampung atau menyimpan basis pengetahuan yang telah diakuisi, dan implementasi sistem ini diterapkan pada aplikasi dengan platform android dengan database menggunakan MySQL.

\subsection{Pengujian Sistem}

a. Usability Testing

Metode ini merupakan metode yang sudah diakui secara luas untuk mengetahui seberapa mudah sebuah produk (laman, aplikasi, teknologi, dll) dapat dimenerti, dipelajari, digunakan, dan disukai secara efektif, efisien dan memuaskan oleh pengguna.

b. Accuracy Testing

Accuracy Testing adalah suatu ukuran yang menunjukkan tingkat kevalidan atau kesahihan suatu instrumen.

\section{Hasil dan Pembahasan}

\subsection{Analisis Kebutuhan}

a. Kebutuhan Alat Pengembang

Pada tahap ini dilakukan pemodelan kebutuhan alat pengembangan yaitu :

1) Hardware
a) Komputer
b) Smartphone Android

2) Software

a) Sistem Operasi Windows 7 Ultimate 64-bit

b) Android Studio

c) Microsoft Word 2013

d) Microsoft Visio 2010

b. Kebutuhan Sistem

1) Model Pemakaian

Model pemakaian dibuat untuk mengetahui seperti apa dan bagaimana nantinya pengguna menggunakan sistem ini.

2) Model Domain

Model domain dibuat untuk mengidentifikasi jenis atau tipe entitas dasar dari sisi konseptual sistem.

3) Model Interface

Model interface dibuat untuk memastikan bahwa apa yang diharapkan oleh yang berkepentingan sesuai dengan apa yang akan dibuat.

\subsection{Pengumpulan Data (Akuisisi Pengetahuan)}

Pengumpulan data dalam penelitian ini mengambil sampel secara langsung di apotek tiga farma yang didapatkan mengenai informasi obat dan beberapa informasi lainnya yang menyangkut dalam basis pengetahuan sistem pakar.

\subsection{Perancangan Sistem}

\section{a. Knowledge Base}

Tabel 1 merupakan basis aturan dari hasil akuisisi pengetahuan yang didapatkan.

Tabel 1 : Basis Aturan 


\begin{tabular}{|c|c|}
\hline $\begin{array}{l}\text { Kode } \\
\text { Rule }\end{array}$ & Aturan \\
\hline $\mathrm{R} 1$ & $\begin{array}{l}\text { IF G0001 OR G0002 OR G0003 } \\
\text { OR G0004 OR G0005 THEN } \\
\text { O0001 }\end{array}$ \\
\hline $\mathrm{R} 2$ & $\begin{array}{l}\text { IF G0006 OR G0007 OR G0008 } \\
\text { THEN O0002 }\end{array}$ \\
\hline $\mathrm{R} 3$ & $\begin{array}{l}\text { IF G0009 OR G0010 OR G0011 } \\
\text { OR G0012 THEN O0003 }\end{array}$ \\
\hline $\mathrm{R} 4$ & $\begin{array}{l}\text { IF G0009 OR G0013 } \\
\text { THENO0004 }\end{array}$ \\
\hline R5 & $\begin{array}{l}\text { IF G0006 OR G0014 OR G0015 } \\
\text { OR G0016 THEN O0005 }\end{array}$ \\
\hline R6 & $\begin{array}{l}\text { IF G0017 OR G0018 THEN } \\
\text { O0006 }\end{array}$ \\
\hline R7 & $\begin{array}{l}\text { IF G0004 OR G0019 OR G0020 } \\
\text { OR G0021 THEN O0007 }\end{array}$ \\
\hline $\mathrm{R} 8$ & $\begin{array}{l}\text { IF G0016 OR G0022 THEN } \\
\text { O0008 }\end{array}$ \\
\hline R9 & IF G0023 THEN O0009 \\
\hline $\mathrm{R} 10$ & $\begin{array}{l}\text { IF G0024 OR G0025 OR G0026 } \\
\text { OR G0027 OR G0028 THEN } \\
\text { O0010 }\end{array}$ \\
\hline $\mathrm{R} 11$ & $\begin{array}{l}\text { IF G0009 OR G0010 OR G0011 } \\
\text { OR G0029 THEN O0011 }\end{array}$ \\
\hline $\mathrm{R} 12$ & $\begin{array}{l}\text { IF G0019 OR G0020 OR G0021 } \\
\text { THEN O0012 }\end{array}$ \\
\hline $\mathrm{R} 13$ & $\begin{array}{l}\text { IF G0020 OR G0030 OR G0031 } \\
\text { THEN O0013 }\end{array}$ \\
\hline $\mathrm{R} 14$ & $\begin{array}{l}\text { IF G0024 OR G0032 THEN } \\
\text { O0014 }\end{array}$ \\
\hline R15 & $\begin{array}{l}\text { IF G0033 OR G0034 THEN } \\
\text { O0015 }\end{array}$ \\
\hline R16 & $\begin{array}{l}\text { IF G0021 OR G0035 OR G0036 } \\
\text { THEN O0016 }\end{array}$ \\
\hline R17 & $\begin{array}{l}\text { IF G0009 OR G0010 OR G0011 } \\
\text { OR G0037 OR G0038 OR G0039 } \\
\text { THEN O0017 }\end{array}$ \\
\hline $\mathrm{R} 18$ & IF G0040 THEN O0018 \\
\hline R19 & $\begin{array}{l}\text { IF G0041 OR G0042 OR G0043 } \\
\text { THEN O0019 }\end{array}$ \\
\hline $\mathrm{R} 20$ & $\begin{array}{l}\text { IF G0020 OR G0021 OR G0031 } \\
\text { THEN O0020 }\end{array}$ \\
\hline $\mathrm{R} 21$ & $\begin{array}{l}\text { IF G0001 OR G0002 OR G0035 } \\
\text { THEN O0021 }\end{array}$ \\
\hline $\mathrm{R} 22$ & $\begin{array}{l}\text { IF G0014 OR G0044 OR G0045 } \\
\text { THEN O0022 }\end{array}$ \\
\hline $\mathrm{R} 23$ & $\begin{array}{l}\text { IF G0046 OR G0047 OR G0048 } \\
\text { THEN O0023 }\end{array}$ \\
\hline
\end{tabular}




\begin{tabular}{|c|l|}
\hline $\begin{array}{c}\text { Kode } \\
\text { Rule }\end{array}$ & \multicolumn{1}{|c|}{ Aturan } \\
\hline R24 & $\begin{array}{l}\text { IF G0049 OR G0050 OR G0051 } \\
\text { THEN O0024 }\end{array}$ \\
\hline R25 & $\begin{array}{l}\text { IF G0008 OR G0052 THEN } \\
\text { O0025 }\end{array}$ \\
\hline R26 & $\begin{array}{l}\text { IF G0002 OR G0021 OR G0035 } \\
\text { THEN O0026 }\end{array}$ \\
\hline R27 & $\begin{array}{l}\text { IF G0053 OR G0054 OR G0055 } \\
\text { THEN O0027 }\end{array}$ \\
\hline R28 & $\begin{array}{l}\text { IF G0056 OR G0057 THEN } \\
\text { O0028 }\end{array}$ \\
\hline R29 & $\begin{array}{l}\text { IF G0005 OR G0035 THEN } \\
\text { O0029 }\end{array}$ \\
\hline R30 & IF G0059 THEN O0030 \\
\hline
\end{tabular}

\section{a. Mesin Inferensi}

Mesin inferensi yang digunakan dalam penelitian ini adalah Forward Chaining yaitu menggunakan IF-THEN sebagai pelacakan solusinya, dan berikut merupakan contoh pelacakan saat costumer menderita gejala dengan kode G0001,G0002, G0003.

$\mathrm{R} 1=$ if $\mathrm{G} 0001$ or G0002 or G0003 then O0001

$\mathrm{R} 2=$ if $\mathrm{G} 0001$ or $\mathrm{G} 0002$ or $\mathrm{G} 0003$ then $\mathrm{O} 0023$

$\mathrm{R} 3=$ if $\mathrm{G} 0001$ or $\mathrm{G} 0002$ or $\mathrm{G} 0003$ then $\mathrm{O} 0029$

Dari ketiga rule tersebut maka aka disimpan 3 jenis obat dengan kode obat O0001, O0023, O0029. Kemudian dari obat obat tersebut akan diambil berdasarkan nilai $\mathrm{Z}$ terbesar dan obat lainnya akan disimpan sebagai obat alternatif.

b. Penarikan Kesimpulan

Gambar 1 merupakan alir data dari penarikan kesimpulan untuk rekomendasi obat yang tepat.

Berikut merupakan langkah perhitungan nilai $\mathrm{Z}$ untuk gejala input adalah G0001, G0002 berdasarkan acuan gambar 1.

1) Crips, pengambilan nilai tegas yang dimiliki tiap gejala inputan user.

2) Rule, untuk mencari obat yang mengandung tiap gejala yang diinputkan user, misal dihasilkan obat O0001 dengan obat O0021.

3) Agregasi, penentuan nilai keanggotan dari tiap gejala-obat, misal didapat nilai tegas G0001-O0001 (0.91),G0001-O0021 (0.65), G0002-O0001 (0.76), G0002-O0021 (0.65) maka dihitung nilai keanggotaan dari tiap gejala obat seperti berikut :

$\alpha=\frac{z-a}{b-a}=(0.91-0.5) /(0.98-0.5) \alpha=0.85$ (G0001-O0001) etc.

4) Defuzzyfikasi, perhitungannya menggunakan rumus 1, ketika dihitung maka akan menghasilkan nilai $Z$ dari masing-masing obat adalah O0001(0.828) dan O0021(0.765). kemudian nilai $\mathrm{Z}$ dibandingkan dan diambil yang terbesar, yaitu $\mathrm{O} 0001$ dengan nilai $\mathrm{Z}$ sebesar 0.828 .

5) Output, setelah didapatkan nilai $\mathrm{Z}$ maka akan dioutputkan hasil dari informasi obat yang direkomendasikan untuk costumer. 


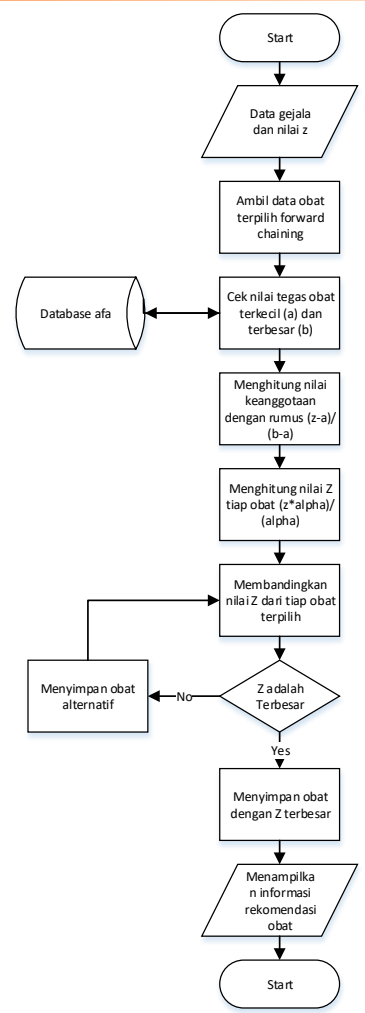

Gambar 1 : Flowchart Kesimpulan

c. Pemodelan Data

a. Use Case Diagram

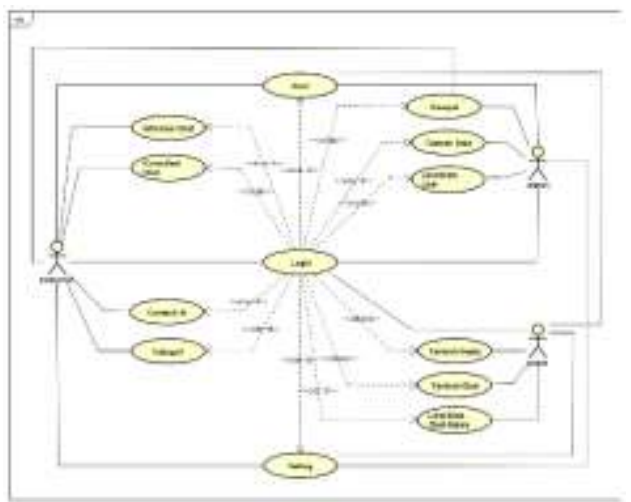

Gambar 2: Use Case Diagram Aplikasi Rekomendasi Obat

Pada gambar 2 dijelaskan bahwa terdapat 3 actor dengan berbagai fitur yang dapat diakses dari setiap actor yang satu dengan yang lainnya.

b. Class Diagram 


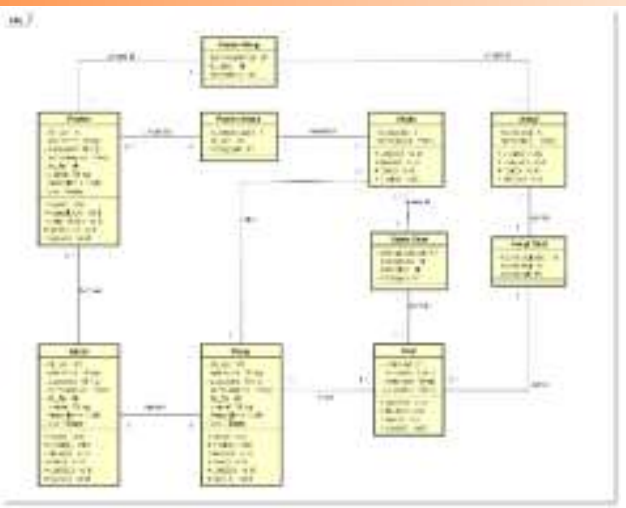

Gambar 3 : Class Diagram Database

Gambar 3 menjelaskan mengenai desain database yang akan diimplementasikan kedalam sistem.

d. Interface System

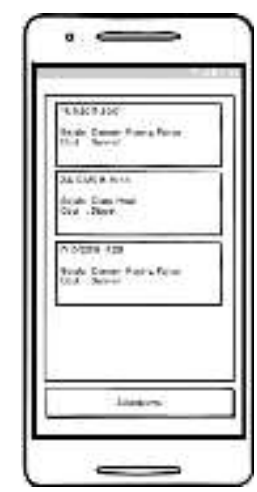

Gambar 4 : Interface Hasil Konsultasi

Gambar 4 menjelaskan mengenai rancangan dari hasil konsultasi obat yang dioutputkan.

\subsection{Implementasi}

a. Login

Gambar 5 merupakan hasil implementasi dari rancangan login yang dibuat

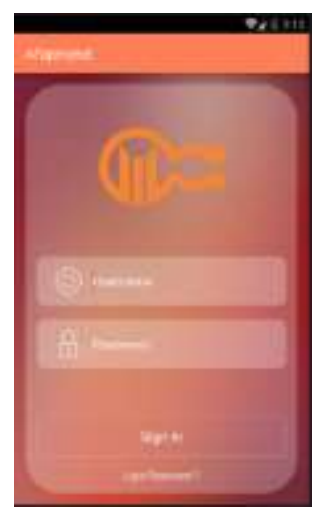

Gambar 5 : Tampilan Form Login

b. Gejala Konsultasi (Costumer)

Saat costumer akan melakukan konsultasi maka akan diminta untuk memasukan gejala yang dirasakan, seperti pada gambar 6 . 


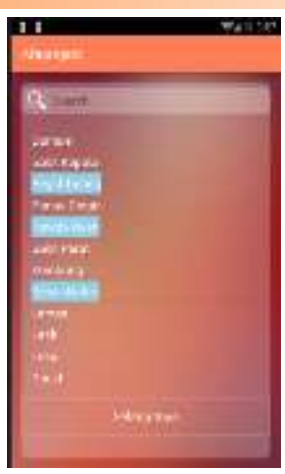

Gambar 6 : Implementasi Gejala Konsultasi

Setelah memilih, maka sistem akan menampilkan hasil obat, seperti gambar 7.

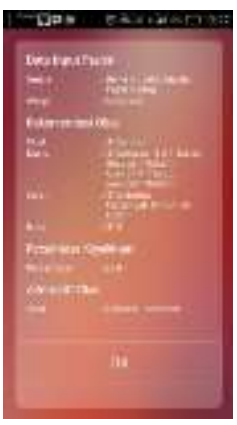

Gambar 7 : Hasil Konsultasi

c. Tambah Obat (Pakar)

Pakar dapat menambah obat baru seperti pada gambar 8 .

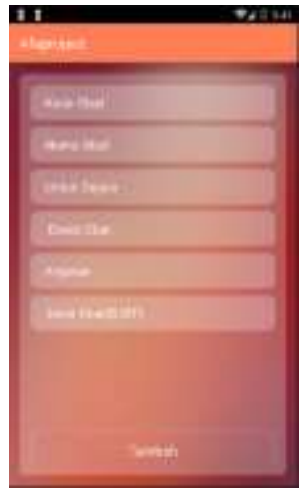

Gambar 8 : Tambah Obat

\subsection{Pengujian Sistem}

a. Usability Testing

Usability Testing dibagikan dalam bentuk kuesioner ke 20 responden dengan perhitungannya adalah :

$$
\text { SUPRQ }=\frac{\text { Jumlah nilai yang diperoleh }}{\text { Jumlah nilai maksimal }} \times 100 \%
$$

Dari hasil yang diisikan responden dan kemudian dihitung didapatkan hasil sebesar 88,25\% dan berdasarkan ukuran nilai $S U P R-Q$ maka nilai tersebut merupakan nilai dengan hasil Excelent. 
b. Accuracy Testing

1) Accuracy Pakar-Sistem

Uji akurasi hasil rekomendasi obat yang ditampilkan sistem dengan yang direkomendasikan oleh pakar diujikan pada 15 kasus yang ada, dari ke-15 kasus tersebut obat dihitung dengan rumus akurasi Nilai Keakuratan $=\frac{15}{15} \times 100 \%$

Dari rumus tersebut didapatkan hasil akurasi adalah sebesar $100 \%$.

2) Accuracy Perhitungan Tsukamoto

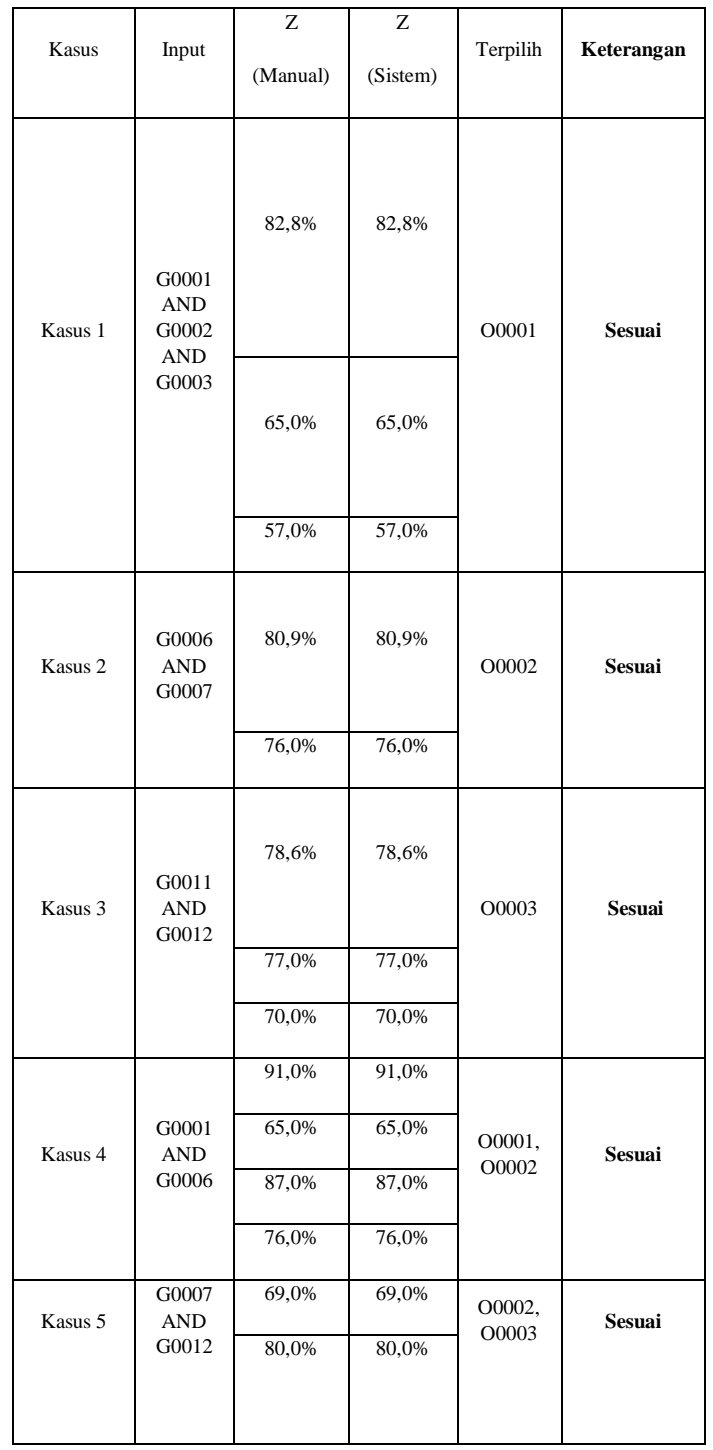

Tabel 2 : Uji Akurasi Perhitungan

Berdasarkan tabel 2 dan rumus akurasi, didapatkan hasil pengujian akurasi perhitungan $\mathrm{Z}$ manual dengan sistem sebesar $100 \%$.

\section{Penutup}

\subsection{Kesimpulan}

Berdasarkan hasil penelitian dan pembahasan, dapat disimpulkan beberapa hal sebagai berikut:

a. Penelitian ini telah menghasilkan aplikasi sistem pakar berbasis mobile untuk merekomendasikan obat non-resep dokter. 
b. Berdasarkan pengujian yang dilakukan dengan menggunakan Usability Testing didapatkan bahwa aplikasi yang dihasilkan dalam penelitian ini adalah grade B dan termasuk excelent.

c. Pengujian berdasarkan Accuracy Testing untuk perbandingan rekomendasi obat sistem dan pakar diperoleh hasil akurasi sebesar 100\% dari banyaknya 15 kasus yang diuji coba. Sedangkan untuk perbandingan nilai $\mathrm{Z}$ manual dengan sistem didapatkan hasil akurasi sebesar $100 \%$ sehingga sistem dianggap sesuai untuk digunakan.

\subsection{Saran}

Untuk penelitian selanjutnya dapat dikembangkan sistem pakar yang dapat memberikan rekomendasi obat secara kesuluruhan tidak tercangkup hanya pada obat non-resep dokter saja.

\section{Daftar Pustaka}

${ }^{[1]}$ Hutahaean, J., Siagian, Y., \&Pasaribu, E. S., (2015). Expert System Untuk Mendiagnosa Penyakit Tanaman Buah Berbasis Web, Riau Journal Of Computer Science, 1(1), 9-15.

${ }^{[2]}$ Depkes RI., (2008). Profil Kesehatan Indonesia. PT. Gramedia Pustaka Utama. Jakarta.

${ }^{[3]}$ Zadeh, L.A. (1965). Fuzzy Sets. Information and Control, 8 : 338-353.

${ }^{[4]}$ Setiadji., (2009). Himpunan dan Logika Samar serta Aplikasinya, Graha Ilmu, Yogyakarta. 252.

${ }^{[5]}$ Kusumadewi., (2004). Aplikasi Logika Fuzzy untuk Pendukung Keputusan, Graha Ilmu, Yogyakarta. Halaman 252.

${ }^{[6]}$ Pujiyanta A., \& Pujiantoro A., (2012). Sistem Pakar Penentuan Jenis Penyakit Hati dengan Metode Inferensi Fuzzy Tsukamoto. Jurnal Informatika, 6(1), 617-629

${ }^{[7]}$ Nabilah G P., \& Kusumadewi S., (2015). Fuzzy Inference System untuk Penentuan Resiko Kanker Payudara. Prosiding SNATIF. Kudus.

${ }^{[8]}$ Waluyo., Didik Nugroho., Kustanto. (2015). Sistem Pakar Diagnosa Penyakit DBD dan Demam Tifoid dengan Metode FuzzyTsukamoto. Jurnal TIKomSiN, 1(3), 17-24.

${ }^{[9]}$ Kusumadewi. (2006). Fuzzy Multi-Attribute Decision Making. Graha Ilmu. Yoggyakarta. Halaman 368.

${ }^{[10]}$ Turban, E., dkk. 2005. Decision Support Systems and Intelligent Systems. Yogyakarta: Andi Offset. 